\title{
LOS TRABAJOS DE ARTE EN EL IV CONGRESO MEXICANO DE HISTORIA
}

$P O R$

\section{MANUEL TOUSSA INT}

I A Sección Quinta del IV Congreso Mexicano de Historia, que tuvo luL gar en la ciudad de Morelia los dias 21 a 27 del mes de enero de 1940, tuvo a su cargo todos los trabajos relacionados con la Historia del Arte, la Enseñanza de la Historia y la Bibliografia. Queremos hacer una breve reseña de los trabajos relativos a Historia del Arte para que el público estudioso pueda darse cuenta de ciertos progresos que pueden haberse desprendido de este Congreso. En general, es lo único que se obtiene en tales Congresos de Historia; es un absurdo pretender una unificación de criterio en lo que se refiere a problemas históricos: la Historia, actividad multiforme y esencialmente personal, será como cada verdadero historiador quiera que sea. Si no es así, carecerá de mérito para ser una simple reseña sobre esquemas oficiales. Así pues, del valor de algunos trabajos presentados y de las relaciones entre historiadores que, al ponerse en contacto aclaran muchos problemas que antes no conocian, dependen los triunfos de esta clase de reuniones. Por eso puede afirmarse sin ambajes, que el IV Congreso Mexicano de Historia, fué un éxito.

Seis fueron los estudios acerca de Historia artística que estudió la Sección Quinta: "Historia del bordado en México", por el señor profesor don 
Higinio Vázquez Santa Ana; "Reseña Histórica y Anecdótica de la Música en México", por el señor don Hernán Rosales; "De la Crítica del Arte en México. Ignacio Manuel Altamirano. 1880" y "Para la Historia de la Tipografía Colonial", por Justino Fernández; "El Drama Mexicano desde la Revolución hasta 1940", por Anna L. Oursler y "La Primitiva Catedral de Michoacán", por Manuel Toussaint.

El estudio del señor Vázquez Santa Ana, a pesar de su gran extensión, no fué un estudio metódico del asunto, sino una reseña con tendencias a demostrar lo que nadie ha pretendido negar nunca: que existió una rama del arte dedicado al bordado que floreció brillantemente. En la misma sesión en que se leyó su trabajo, se le hizo notar un grave error, a saber, que confunde el arte plumario con el arte del bordado, pues si bien los mosaicos de pluma sustituyeron en algunas ocasiones a los objetos bordados, nunca pueden considerarse como idénticos. El mosaico de pluma es una manifestación sui géneris de la época precortesiana que subsiste brillantemente durante el siglo $\mathrm{XVI}$, en tanto que el bordado es algo completamente diverso.

"La Reseña Histórica y Anecdótica de la Música en México", por Don Hernán Rosales, tiene un carácter eminentemente periodístico como su autor lo indicó; es un trabajo ameno en el que no se pretende haber realizado investigaciones propias, sino sólo reunir datos ya conocidos. Se le hicieron algunas observaciones de elementos omitidos que el autor aceptó buenamente.

El primer trabajo de Justino Fernández: "De la Crítica de Arte en México.-Ignacio Manuel Altamirano. 1880", es de sumo interés, pues todavía no se ha iniciado en México un estudio comparativo de la Crítica de Arte. Saber cómo se juzgó de la obra artística a través de los diversos tiempos, ayuda enormemente a comprender el fenómeno de arte. De una obra más amplia Justino Fernández escogió el pasaje relativo a Ignacio Manuel Altamirano. E1 famoso tribuno liberal, al hacer apreciaciones artísticas, no puede prescindir de su gran talento; pero sus puntos de vista, por una paradoja curiosa, presentan en contratse con su credo libertario su manera de pensar acerca del arte, que no puede salir de los límites de lo clásico. Será necesario conocer todo el trabajo para poder emitir un juicio integral acerca de él. El segundo tema tratado por Justino Fernández, "Para la Historia de la Tipografia Colonial", trata un punto también de gran importancia: el grabado de punzones para matrices de tipos. El asunto no está muy bien dilucidado en nuestra Historia Tipográfica, pues aunque es seguro que en la época colonial se comenzaton a grabar los punzones, no hay datos concretos so- 
bre el asunto, y las letras obtenidas con ellos no presentan la calidad artística de los punzones grabados por Don Jerónimo Antonio Gil, el ilustre fundador de la Academia de San Carlos, que es a quien se refiere el documento publicado por Justino Fernández. Debe considerarse pues este trabajo como uno de los primeros aportes para la historia de esta rama de nuestras artes industriales.

La señorita Anna L. Oursler, distinguida profesora norteamericana, realizó un amplio estudio acerca del drama mexicano, desde la Revolución hasta 1940. La parte presentada en el Congreso de Historia es sólo un fragmento de la obra, y el total está destinado para optar al grado de Doctor Universitario. El trabajo mencionado adolece de un defecto de título, pues la autora habla no simplemente de drama, sino de diversas obras teatrales, que no presentan la caracteristica dramática. Sin embargo, hay que observar que la autora procede de acuerdo con la índole de su idioma, en el cual la palabra drama caracteriza no sólo a la obra que en español consideramos en la limitación dramática, sino toda la producción teatral. Diversas objeciones se le hicieron en cuanto al fondo del trabajo; la autora parece muy influenciada con la idea de que la Revolución Mexicana ha creado un nuevo género teatral, cosa que no es exacta; además, supone que el florecimiento que ella encuentra en el teatro actual -florecimiento que es muy relativo en cuanto al verdadero mérito de ese teatro-, se debe a la libertad de expresión de que no se gozaba en la época colonial. Esta observación no sólo es falsa, sino que hay que hacer notar que los más excelentes autores teatrales que México ha dado al mundo como son: Juan Ruiz de Alarcón y Sor Juana Inés de la Cruz, florecieron precisamente en esa época. Por lo que se refiere al teatro popular actual, que es una mezcla incongruente de alusiones políticas y escenas pornográficas, la autora no da un juicio definitivo, sino que simplemente se dedica a enlazar a los actores que han obtenido más éxito. A pesar de estas limitaciones creemos que el trabajo será útil, ya publicado en el conjunto que la autora ha realizado, porque permitirá completar investigaciones parciales que son las únicas que existen.

Finalmente, quien esto escribe, formuló un trabajo acerca de "I mitiva Catedral de Michoacán". La tesis sostenida es que Don Vasco de Quiroga no construyó un edificio especial en la población de Tzintzuntzan para sede de su Catedral, sino que aprovechó un templo modestísimo con la advocación de San Francisco, para tomar la posesión legal de su Obispado y que al dia siguiente tomó posesión en Pátzcuaro, donde comenzó desde 
luego la construcción de su Catedral; ésta, desde el punto de vista canónico sólo existió en Tzintzuntzan mientras tardó la construcción del templo de Pátzcuaro. Don Vasco hizo en seguida el traslado, y poco tiempo después recibió las aprobaciones necesarias. Si esta tesis está justificada con los documentos que se presentan, es necesario modificar casi todos los tratados de Historia de Michoacán, en que se viene repitiendo la opinión contraria : que Don Vasco estableció su iglesia en Tzintzuntzan, construyó allí un templo provisional y después de algún tiempo, encontrando que la población tenía muchos defectos, trasladó su iglesia a Pátzcuaro.

Independientemente de estos trabajos se presentaron otros muchos; pero como no es nuestro ánimo reseñar sino sólo los que se refieren a la Historia del Arte, damos por terminada nuestra tarea, que prueba, según creemos, que la Sección Quinta desarrolló una intensa labor. Indudablemente las demás hicieron lo propio, como puede verse de los informes finales. De desearse es que cuanto antes se publique la Memoria del Congreso para que todos estos trabajos vean la luz pública y contribuyan a esclarecer muchos puntos dudosos de nuestra Historia en sus diversas manifestaciones. 